\title{
Hardening and Toughening Mechanisms of Cemented Carbides with Plate-Like WC Grains Prepared by Seeding
}

\author{
Kun Liu, Lihui Zhu and Ranran Tu \\ Shanghai Key Laboratory of Modern Metallurgy \& Materials Processing, Shanghai University, Shanghai 200072, P. R. China \\ WC-10Co (mass pct.) cemented carbides containing plate-like WC grains were prepared by using plate-like WC single crystals as seeds. \\ With the increase of seed addition amount, more and bigger plate-like WC grains are formed, the hardness and transverse rupture strength (TRS) \\ increase first and then decrease. When 2.5 mass $\%$ seeds are added in WC-10Co, the density is hardly affected, whereas the hardness and TRS \\ increase simultaneously, especially TRS increases by $12.8 \%$. The hardening and toughening mechanisms of WC-10Co cemented carbides with \\ plate-like WC grains were discussed. [doi:10.2320/matertrans.M2010380]
}

(Received November 10, 2010; Accepted December 27, 2010; Published April 1, 2011)

Keywords: seed, plate-like tungsten carbide grain, microstructure, mechanical properties, hardening and toughening mechanisms

\section{Introduction}

Cemented carbides are widely used as cutting tools, rock drill tips and wear-resistant components due to high hardness, good strength, excellent wear and erosion resistance. However, the toughness of cemented carbides is relatively poor, and it is difficult to improve the hardness and strength simultaneously. In recent years, the researchers have found that the toughness of cemented carbides with plate-like WC grains can be increased without the decrease of hardness. ${ }^{1-6)}$ It also exhibits higher fatigue strength, creep resistance and thermal shock resistance at elevated temperatures than traditional cemented carbides. ${ }^{7)}$ Therefore, cemented carbides with plate-like WC grains will have a great future.

WC-Co cemented carbides with highly oriented plate-like triangular prismatic WC grains have been successfully fabricated by using special $\mathrm{W}+\mathrm{C}$ mixed powders, and plate-like $\mathrm{WC}$ grains are originated from the flattened $\mathrm{W}$ particles by ball-milling. ${ }^{8)} \mathrm{Co}_{x} \mathrm{~W}_{y} \mathrm{C}_{z}+\mathrm{C}$ can also be utilized as the main starting materials to prepare the cemented carbides with plate-like triangular prismatic WC grains. ${ }^{4)}$ When these two methods are used, the carbon content must be controlled strictly, since the properties of cemented carbides are strongly related with the carbon content. The formation of plate-like WC grains is facilitated by the addition of $\mathrm{TiC}^{9)}$ or $\mathrm{Y}_{2} \mathrm{O}_{3}{ }^{10)}$ in the cemented carbides, but the properties of cemented carbides may be changed by the introduction of other particles.

Cemented carbides with plate-like WC grains can be prepared by adding plate-like WC single crystal particles as seeds. ${ }^{11)}$ It is not necessary to worry about the impairment of properties because only WC particles are used as starting materials. Especially, the size and amount of plate-like WC grains can be controlled by changing the addition amount of plate-like seeds, making it possible to obtain the cemented carbides with good comprehensive properties. In this paper, WC-10Co (mass pct.) cemented carbides with plate-like WC grains were prepared by the addition of plate-like WC seeds. The effect of seed addition amount on the microstructure and mechanical properties of WC-10Co was studied, and the hardening and toughening mechanisms were discussed.

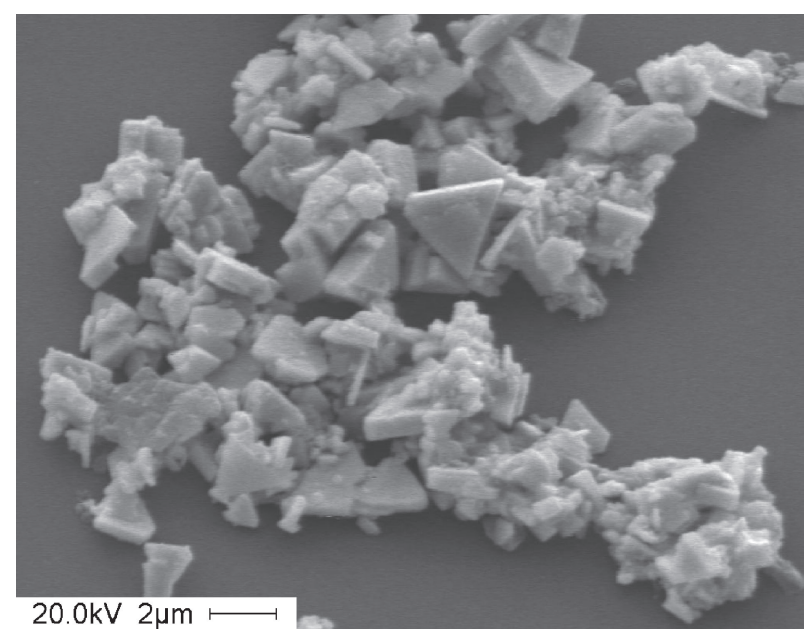

Fig. 1 SEM micrograph of plate-like WC seeds.

\section{Experimental Procedure}

WC powders with FSSS particle size of $3.0 \mu \mathrm{m}$ and commercial Co powders were used as starting powders. WC-Co powders according to a certain weight ratio were prepared by high-energy ball-milling. The ball-milling time was $24 \mathrm{~h}$, the weight ratio of ball-to-powder was $4: 1$, and the rotation speed was $200 \mathrm{r} / \mathrm{min}$. The average particle size of WC-Co powders decreased to $1 \mu \mathrm{m}$ after ball-milling. Plate-like WC single crystal particles by molten salt synthesis were used as seeds, the particle size ranged from 1 to $3 \mu \mathrm{m}$, as shown in Fig. 1. 0, 2.5, 5 and 10 mass\% platelike WC seeds were added into the ball-milled WC-Co powders. No matter how many seeds were added, the mass fraction of Co was fixed to be 10 mass $\%$ in the final component. Subsequently, the well-mixed WC-10 mass\% Co composite powders were pressed into green compacts with dimension of $5 \mathrm{~mm} \times 5 \mathrm{~mm} \times 35 \mathrm{~mm}$, and then sintered at $1460^{\circ} \mathrm{C}$ for $40 \mathrm{~min}$ in vacuum.

The density of samples was determined by the Archimedes method. The coercivity $\left(h_{\mathrm{c}}\right)$ was measured by Coercimeter 93-1. The microstructure was observed by Hitachi S-570 

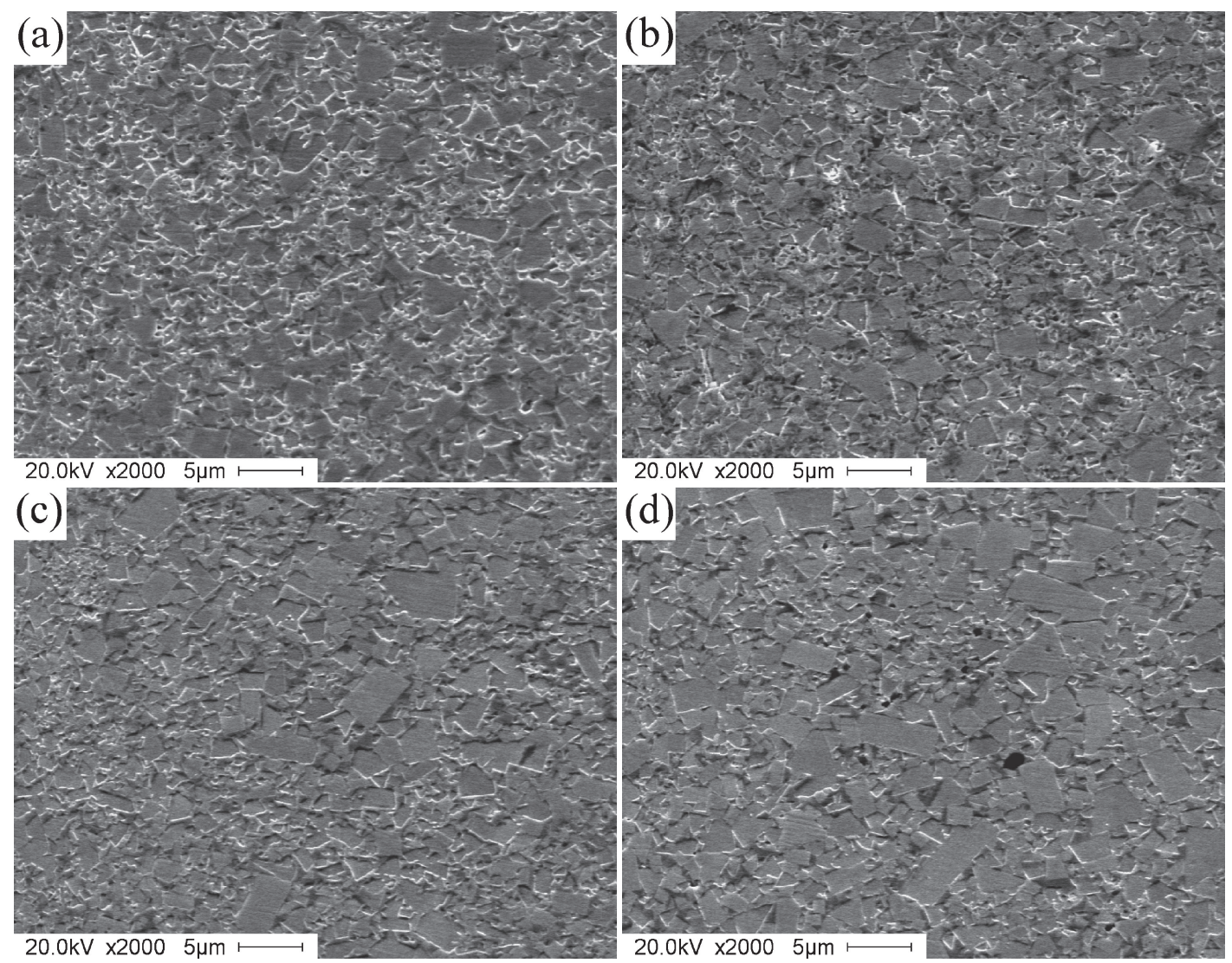

Fig. 2 Microstructure of the WC-10Co cemented carbides with different seed addition: (a) 0; (b) 2.5 mass $\%$; (c) 5 mass $\%$; (d) 10 mass $\%$.

scanning electron microscope (SEM). The hardness was measured on polished surfaces using 69-1 hardness tester. An electronic universal testing machine was used to carry out the 3-point transverse rupture strength bend test, and the load-displacement curve was recorded. The transverse rupture strength (TRS) can be evaluated as follows:

$$
\sigma=3 P L / 2 b h^{2}
$$

where $\sigma$ is the TRS, MPa; $P$ is the applied force to fracture, $\mathrm{N} ; L$ is the distance between two parallel supports, $\mathrm{mm} ; b$ and $h$ is the width and height of the samples respectively, $\mathrm{mm}$.

\section{Results}

\subsection{The effect of seed addition on the microstructures}

The microstructures of WC-10Co added by $0,2.5,5$ and 10 mass\% plate-like WC seeds are shown in Fig. 2. The addition of plate-like seeds helps the development of platelike WC grains. With the increase of seed addition amount, more plate-like WC grains with more regular shape and bigger aspect ratio are formed, and the average size of WC grains becomes larger. When 10 mass\% seeds are added, the amount of plate-like WC grains and the average grain size reach the maximum values, but there are some pores.

During the liquid phase sintering, the grains grow up through Ostwald Ripening, i.e. small particles dissolve in the liquid phase and the solute atoms diffuse into large particles. In this process, small particles become smaller and smaller, while big particles become bigger and bigger. ${ }^{12)}$ Since most of the matrix powders (average particle size: $1 \mu \mathrm{m}$ ) are smaller than seeds (particle size: $1 \sim 3 \mu \mathrm{m}$ ), WC particles of matrix powders tend to firstly dissolve in the liquid and eventually precipitate on the surfaces of plate-like WC seeds. The further growth of plate-like seeds leads to the formation of plate-like WC grains. However, when too many seeds are added, it is easy to form some solid skeletons due to the agglomeration and overlapping of the plate-like seeds with big size. If the void spaces of the solid skeletons can not be filled in time during the shrinkage, a few pores remain after sintering, as shown in Fig. 2(d).

\subsection{The effect of seed addition on the properties}

Figure 3 shows the variations in density, hardness and TRS of WC-10Co with the seed addition amount. With the increase of seed addition amount, the density tends to decrease (Fig. 3(a)), while the hardness and TRS increase first and then decrease (Figs. 3(b), 3(c)). It is noteworthy that the relative density of WC-10Co is hardly affected by the addition of 2.5 mass\% plate-like WC seeds, the hardness and TRS reach the maximum values simultaneously. Compared with WC-10Co without seeds, the hardness of WC-10Co added by 2.5 mass\% seeds increases slightly, whereas TRS increases by $12.8 \%$.

Figure 3(d) shows that the coercivity of WC-10Co decreases when the amount of seed addition increases. The coercivity can be used as an indicator of WC grain size in cemented carbides when cobalt content is constant. The 

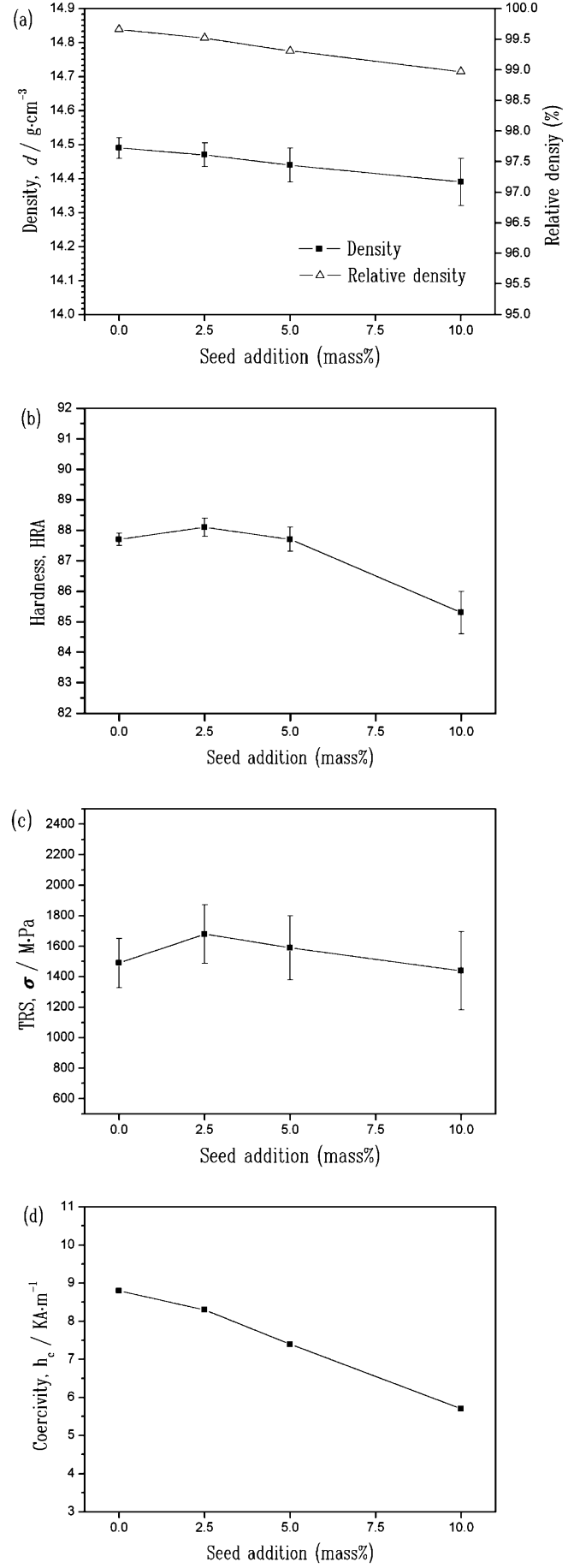

Fig. 3 The effect of seed addition amount on the properties of WC-10Co cemented carbides.

larger the WC grain size is, the lower the coercivity is. ${ }^{13)}$ It further indicates that the grain size of WC increases with the addition of more seeds, which is consistent with the microstructure observation.

\subsection{The effect of seed addition on the fracture}

It is generally accepted that four types of fracture modes may be distinguished in WC-Co cemented carbides: transgranular fracture in the carbides (labeled as $\mathrm{C}$ ), along carbide-carbide interfaces (labeled as $\mathrm{C} / \mathrm{C}$ ), along the carbide-cobalt interfaces (labeled as $\mathrm{B} / \mathrm{C}$ ), and through the
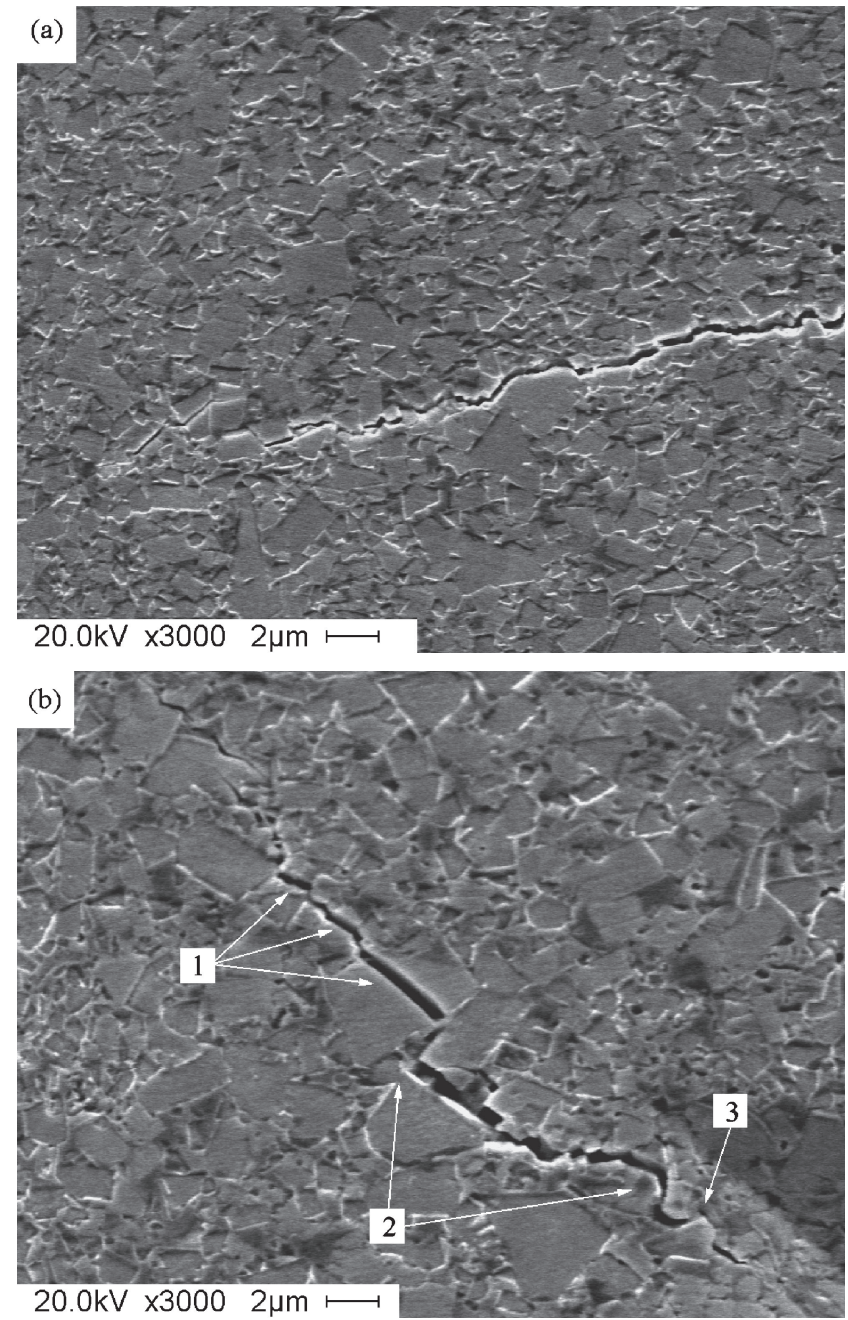

Fig. 4 Indentation crack propagation of WC-10Co cemented carbides without (a) and with (b) the addition of 2.5 mass $\%$ seeds: 1 transgranular fracture, 2 crack deflection, 3 crack bridging.

cobalt phases (labeled as $\mathrm{B}$ ). Fracture $\mathrm{C}$ and $\mathrm{C} / \mathrm{C}$ belong to brittle fracture, while fracture $\mathrm{B} / \mathrm{C}$ and $\mathrm{B}$ belong to ductile fracture. ${ }^{5,14,15)}$ Figure 4 shows the effect of seed addition on the propagation path of the vickers indentation crack. Although WC-10Co added by the seeds still shows a mixed fracture mode including major brittle fracture and minor ductile fracture, an increase in the amount of $\mathrm{C}$ fracture can be observed. After the addition of WC seeds, the path of the indentation crack becomes more tortuous. Crack bridging, which is generated by the ductile binder ligaments over a region behind the crack tip, also happens more easily.

Figure 5 shows the load-displacement curves recorded during the fracture of the cemented carbides with and without the addition of seeds. After the addition of WC seeds, the stress required for fracture (i.e. TRS) increases. In comparison with WC-10Co without seed addition, the curve of WC10Co added by 2.5 mass $\%$ seeds displays a little steeper, indicating that the applied load is higher at the same deformation. The comparison of the area under the loaddisplacement curve suggests that more fracture energy should be consumed during the fracture when WC seeds are added in the cemented carbides. 


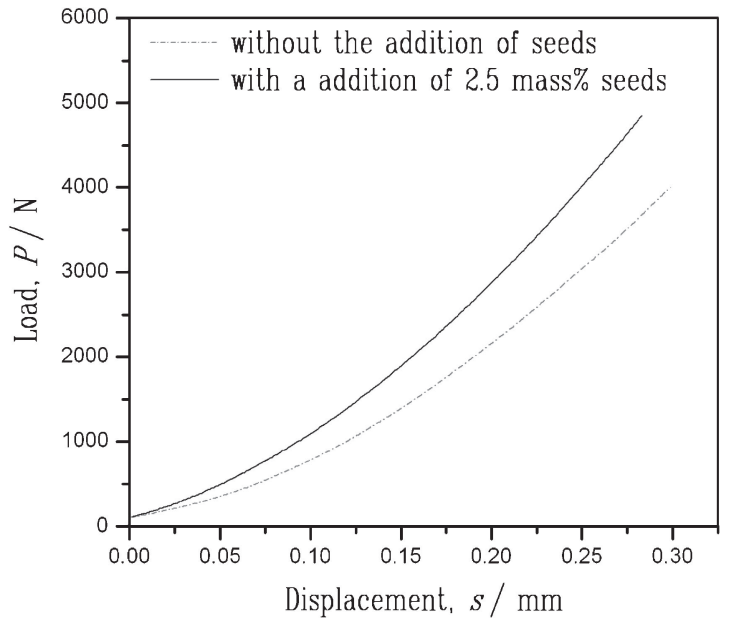

Fig. 5 The effect of 2.5 mass $\%$ seed addition on the load-displacement curve of WC-10Co cemented carbides.

\section{Discussion}

\subsection{The hardening mechanism of $\mathrm{WC}-10 \mathrm{Co}$ with plate- like WC grains}

It is well known that the crystal structure of WC is hexagonal and the hardness is strongly anisotropic. The micro-hardness of the basal facet (0001) is twice as high as that of prismatic facet $(1 \overline{1} 00) .{ }^{3,15)}$ The relative area fraction of harder basal facet increases when the shape of WC crystals changes to a flatter triangular prism. Therefore, it is reasonable to expect that the hardness of cemented carbides increases.

After considering that hardness is probably affected by the shape of WC crystals, Shatov A. V. et al. proposed a modified Lee \& Gurland model for hardness. ${ }^{6}$ ) When the volume fraction of WC phase is very high, the hardness is primarily determined by WC phase. Exactly speaking, the volume fraction and the particle size of WC are the most important factors to control the hardness of WC-Co cemented carbides. ${ }^{16,17)}$ So the hardness of WC-10Co can be expressed as follows:

$$
H V \propto \frac{H_{\mathrm{WC}}^{\mathrm{HP}}}{\sqrt{\frac{P_{\mathrm{WC}}}{P_{\mathrm{WC}}^{0}} \cdot D_{\mathrm{WC}}}}
$$

where $H_{\mathrm{WC}}^{\mathrm{HP}}$, a constant, is the Hall-Petch hardening factors for WC. $D_{\mathrm{WC}}$ is the grain size of WC. $P_{\mathrm{WC}}$ is the shape equiaxiality. ${ }^{9)} P_{\mathrm{WC}}^{0}$ is the initial value of $P_{\mathrm{WC}}$.

It can be seen from eq. (2) that $P_{\mathrm{WC}}$ and $D_{\mathrm{WC}}$ are the two main parameters to determine the hardness of cemented carbides. $P_{\mathrm{WC}}$ decreases when the shape of WC crystals changes to plate-like. ${ }^{9)}$ However, the addition of seeds makes $D_{\text {WC }}$ increase, and $D_{\text {WC }}$ increases with the increase of seed addition amount, as shown in Fig. 6(a). Hence $P_{\mathrm{WC}}$ and $D_{\mathrm{WC}}$ exhibit opposite effects on hardness. In order to estimate the effect of $D_{\mathrm{WC}}$ and $P_{\mathrm{WC}}$ on hardness, eq. (2) can be re-written in the form of:

$$
H V \propto \frac{1}{\sqrt{\frac{P_{\mathrm{WC}} \cdot D_{\mathrm{WC}}}{P_{\mathrm{WC}}^{0} \cdot D_{\mathrm{WC}}^{0}}}}
$$
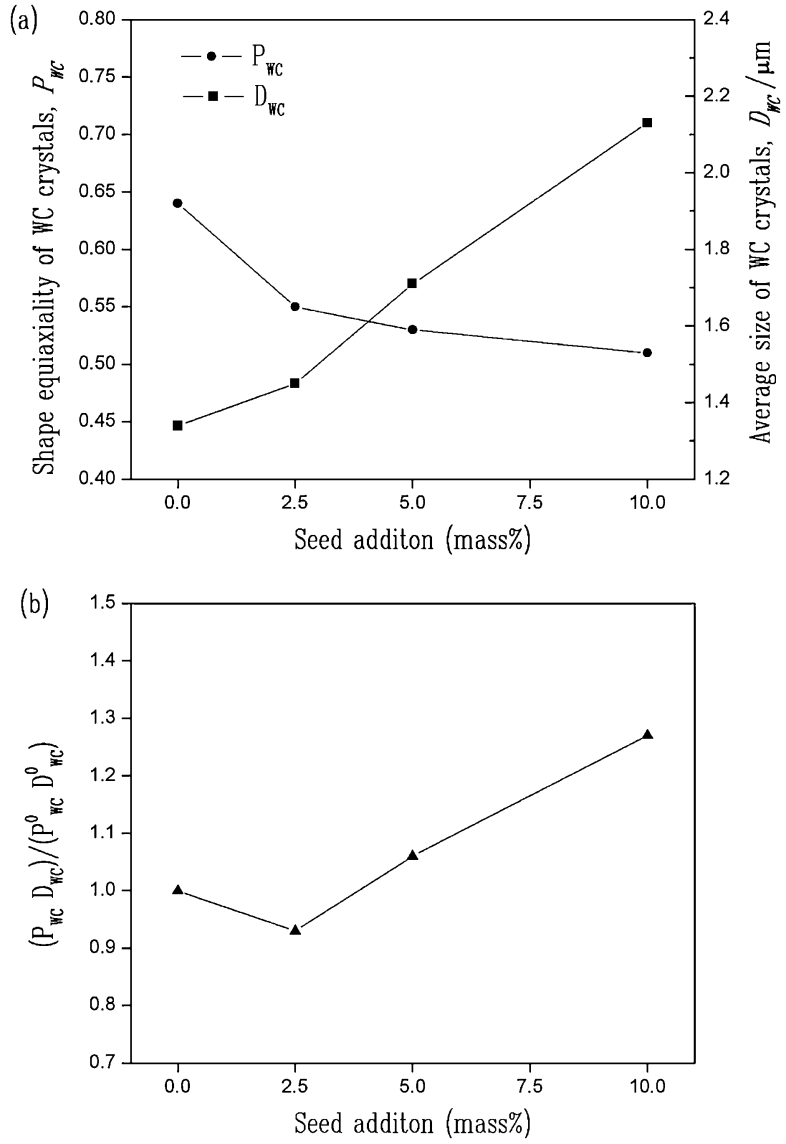

Fig. 6 Microstructure parameters of WC-10Co cemented carbides with different addition amount of seeds.

where $D_{\mathrm{WC}}^{0}$ is the initial value of $D_{\mathrm{WC}}$. The lower the value of $\left(P_{\mathrm{WC}} \cdot D_{\mathrm{WC}}\right) /\left(P_{\mathrm{WC}}^{0} \cdot D_{\mathrm{WC}}^{0}\right)$ is, the higher the hardness is. The variation of $\left(P_{\mathrm{WC}} \cdot D_{\mathrm{WC}}\right) /\left(P_{\mathrm{WC}}^{0} \cdot D_{\mathrm{WC}}^{0}\right)$ with different addition amount of seeds is shown in Fig. 6(b). WC-10Co added by 2.5 mass \% seeds has the highest hardness owing to the minimum value of $\left(P_{\mathrm{WC}} \cdot D_{\mathrm{WC}}\right) /\left(P_{\mathrm{WC}}^{0} \cdot D_{\mathrm{WC}}^{0}\right)$. Thereafter, the value of $\left(P_{\mathrm{WC}} \cdot D_{\mathrm{WC}}\right) /\left(P_{\mathrm{WC}}^{0} \cdot D_{\mathrm{WC}}^{0}\right)$ increases with the increase of seed addition amount. On the other hand, the relative density continuously decreases, which is harmful to the hardness. Consequently, it is the comprehensive effect of $P_{\mathrm{WC}}, D_{\mathrm{WC}}$ and density of the cemented carbides that makes the hardness reach the maximum value when 2.5 mass $\%$ seeds are added, and then it decreases with the further increase of seed addition amount.

\subsection{The toughening mechanism of $\mathrm{WC}-10 \mathrm{Co}$ with plate- like WC grains}

It is found by numerous experiments that TRS of WC$10 \mathrm{Co}$ increases with the increase of WC grain size when WC grains are not very coarse. ${ }^{18-20)}$ As mentioned in chapter 3.2, TRS has a substantial increase after the addition of 2.5 mass $\%$ seeds. The increase of WC grain size brings about the increase of TRS to a certain degree. Besides, the increase of trans-crystalline fracture (C) likely plays a positive role in improving the fracture strength and the toughness, based on the fact that considerable energy is required for crack to cross the $\mathrm{WC}$ crystals. 
The increase in the amount of $\mathrm{C}$ fracture can be ascribed to the following reasons. Firstly, internal defects increase with the increase of WC grain size, so it is easy for the cracks to generate in WC crystals or break through WC crystals. Secondly, the flatter shape of WC crystals increases both the likelihood for the crack tip to meet the bigger basal facets and the average length of the path around WC crystals, thus it is more advantageous to break through WC crystals than to go around it through the cobalt, $\mathrm{WC} / \mathrm{Co}$, and $\mathrm{WC} / \mathrm{WC}$ interfaces. ${ }^{5)}$ Therefore the amount of trans-crystalline fracture through WC increases when the shape of WC crystals becomes flatter triangular prism with lower value of $P_{\mathrm{WC}}$.

The slope of the load-displacement curve increases after the addition of seeds, as seen in Fig. 5, which indicates that more energy is consumed during the crack propagation. In addition to the increase in the amount of trans-crystalline fracture, the crack deflection ${ }^{21)}$ and crack bridging ${ }^{22)}$ play an important role in the improvement of the toughness of the cemented carbides.

When WC crystals become larger and flatter due to the addition of seeds, the crack deflection and crack bridging are activated (see Fig. 4). The intense crack deflection results from the decreased $P_{\mathrm{WC}}$, the increased grain size and the increased amount in cleavage of WC crystals. Correspondingly, both the total distance of crack propagation and the total area of the crack surface increase. WC grain size increases when the seeds are added in WC-10Co. According to the famous stereological relationship, ${ }^{15)}$ the binder mean free path increases as a result of the increase in WC grain size. Thus the crack bridging generated behind the crack tip takes place easily, and the crack tip opening displacement (CTOD) decreases. It will have a great effect on the improvement of toughness. Owing to the crack deflection and crack bridging, extra energy is dissipated during the propagation of cracks, and the toughness and the fracture strength of WC-10Co added by the seeds are consequently increased.

However, with the increase of seed addition amount, the relative density continuously decreases, which deteriorates the properties of cemented carbides. As a result, a downward trend appears subsequently for TRS when added by more than 2.5 mass $\%$ seeds.

\section{Conclusions}

WC-10Co cemented carbides with plate-like WC grains were prepared by adding plate-like WC single crystal particles as seeds. The following conclusions are drawn:

(1) The addition of plate-like seeds facilitates the development of plate-like WC grains. With the increase of seed addition amount, more and bigger plate-like WC grains are formed.

(2) With the increase of seed addition, the density tends to decrease, while the hardness and TRS increase first and then decrease. When 2.5 mass $\%$ seeds are added in WC-10Co, the density is hardly affected, whereas the hardness and TRS increase simultaneously, especially TRS increases by $12.8 \%$.
(3) When the shape of WC crystals changes to plate-like, the shape equiaxiality $P_{\mathrm{WC}}$ decreases. However, WC grain size $D_{\mathrm{WC}}$ increases with the increase of seed addition amount. WC-10Co added by 2.5 mass $\%$ seeds has the highest hardness owing to the minimum value of $\left(P_{\mathrm{WC}} \cdot D_{\mathrm{WC}}\right) /$ $\left(P_{\mathrm{WC}}^{0} \cdot D_{\mathrm{WC}}^{0}\right)$.

(4) As the shape of WC crystals becomes flatter triangular prism with lower value of $P_{\mathrm{WC}}$, the amount of transcrystalline fracture in WC crystals increases, thus considerable energy is required for crack to cross WC crystals. Besides, the crack deflection and crack bridging play an important role in the improvement of the toughness of the cemented carbides.

\section{Acknowledgements}

The work was supported by the Science Innovation Foundation of Shanghai Municipal Commission of Education under the grant 09YZ26. The authors were grateful for the help provided by Mr. Zhilin Li during the experiments.

\section{REFERENCES}

1) M. Kobayashi, K. Kitamura and S. Kinoshita: Plate-crystalline tungsten carbide-containing hard alloy, composition for forming plate-crystalline tungsten carbide and process for preparing said hard alloy, (Patent 5993506, US, 1997).

2) T. Saito, Y. Taniguchi, M. Kobayashi and K. Kobori: Proc. 1998 Int. Conf. on Powder Metallurgy and Particulate Materials, ed. by J. J. Oakes and J. H. Reinshagen, (M.P.I.F., 1998) pp. 147-155.

3) S. Kinoshita, T. Saito, M. Kobayashi and K. Hayashi: J. Jpn. Soc. Powder Powder Metall. 47 (2000) 526-533.

4) K. Kitamura, M. Kobayashi and K. Hayashi: J. Jpn. Soc. Powder Powder Metall. 48 (2001) 621-628.

5) A. V. Shatov, S. A. Firstov and I. V. Shatova: Int. J. Refract. Met. Hard Mater. 26 (2008) 68-76.

6) A. V. Shatov, S. S. Ponomarev and S. A. Firstov: Int. J. Refract. Met. Hard Mater. 27 (2009) 198-212.

7) S. Kinoshita, M. Kobayashi and K. Hayashi: J. Jpn. Soc. Powder Powder Metall. 49 (2002) 299-305.

8) S. Kinoshita, T. Saito, M. Kobayashi and K. Hayashi: J. Jpn. Soc. Powder Powder Metall. 48 (2001) 51-60.

9) A. V. Shatov, S. A. Firstov and I. V. Shatova: Mater. Sci. Eng. A 242 (1998) 7-14.

10) L. Zhang, S. Chen, W. D. Schubert and B. Huang: J. Cent. S. Univ. Technol. 11 (2004) 119-123.

11) L. Zhu, Z. Li, Q. Huang, S. Zhu and L. Wang: preparation method of cemented carbide containing large plate-like WC grains, (Patent 200810200320, China, 2008).

12) C. H. Allibert: Int. J. Refract. Met. Hard Mater. 19 (2001) 53-61.

13) I. Topic, H. G. Sockel, P. Wellmann and M. Goken: Mater. Sci. Eng. A 423 (2006) 306-312.

14) L. S. Sigl and H. E. Exner: Metall. Trans. A 18 (1987) 1299-1308.

15) B. Roebuck and E. A. Almond: Int. Mater. Rev. 33 (1988) 90-110.

16) C.-S. Kim: PhD thesis, (C.M.U., US, 2004) pp. 56-57.

17) V. T. Golovchan: Int. J. Refract. Met. Hard Mater. 26 (2008) 301-305.

18) H. E. Exner and J. Gurland: Powder Metall. 13 (1970) 13-31.

19) H. L. Roux: Int. J. Refract. Met. Hard Mater. 3 (1984) 99-100.

20) E. A. Almond: Mat. Sci. Monogr. (1984) 331-347.

21) C. Nischik, M. M. Seibold, N. A. Travitzky and N. Claussen: J. Am. Ceram. Soc. 74 (1991) 2464-2468.

22) D. B. Marshall, W. L. Morris, B. N. Cox and M. S. Dadkhah: J. Am. Ceram. Soc. 73 (1990) 2938-2943. 